\title{
O uso das Tecnologias Digitais como Ferramentas Cognitivas
}

\author{
Patrícia Fernanda da Silva - patriciasilvaufrgs@gmail.com
}

\begin{abstract}
This article describes the speeches brought by the panelists during the I Pedagogical Innovation Workshop of the Federal University of Rio Grande do Sul. During the panel, teachers representing the Engineering, Dentistry and Informatics course presented some needs, methodologies, approaches and projects that are being studied. developed at the institution in undergraduate and postgraduate courses from the use of digital technologies. Later the use of these tools is approached, showing their importance to support the students learning, as well as the use of digital technologies as cognitive tools. Finally, reflections are brought about how it is possible to lead students to think from the use of digital technologies.

Resumo. Este artigo descreve as falas trazidas pelos painelistas durante o I Workshop de Inovação Pedagógica da Universidade Federal do Rio Grande do Sul. Durante o painel professores representantes do curso de Engenharia, Odontologia e de Informática apresentaram algumas necessidades, metodologias, abordagens e projetos que estão sendo desenvolvidos na instituição nos cursos de graduação e pós-graduação a partir do uso das tecnologias digitais. Posteriormente o uso destas ferramentas é abordado, mostrando a sua importância para apoiar a aprendizagem dos alunos, bem como o uso das tecnologias digitais como ferramentas cognitivas. Para finalizar, são trazidas reflexões de como é possível levar os alunos a pensar a partir da utilização das tecnologias digitais.
\end{abstract}

\section{Introdução}

O uso das Tecnologias Digitais mostra-se a cada dia mais importante. Computadores, laptops, smartphones e tablets fazem parte dos utensílios a serem carregados diariamente e considerados pela maioria das pessoas como indispensáveis ao sair de casa, assim, como documentos, dinheiro ou cartão de crédito.

Vivemos em um contexto em que o Uso das Tecnologias, mídias e redes sociais se intensificam e quase tudo o que fazemos estão envolvendo estas ferramentas, seja no contexto de trabalho, no lazer ou até mesmo no ambiente de estudo.

No entanto, em determinadas universidades e salas de aula, embora os alunos estejam frequentemente conectados, é necessário desligar o smartphone, abrir o caderno e iniciar a cópia de exercícios a serem resolvidos.

Diante deste contexto, com a preocupação de que diferentes metodologias com o uso de Tecnologias Digitais possam chegar às salas e proporcionar que os alunos possam discutir, refletir e trabalhar colaborativamente, foi desenvolvido o I Workshop de Inovação Pedagógica na Universidade Federal do Rio Grande do Sul, com o intuito de que docentes pudessem compartilhar e pensar em metodologias que venham ao encontro destas habilidades no trabalho em sala de aula, nos cursos de graduação e pós-graduação da referida universidade. 
Durante dois dias de encontros, professores e servidores da UFRGS ${ }^{1}$ se reuniram para conversar e trocar experiências com palestrantes e painelistas oriundos de universidades do Chile, Maranhão e do Instituto Federal Fluminense do Rio de Janeiro para discutir e apresentar situações com abordagens voltadas para inovações, o Ensino Híbrido, sala de aula invertida e rotação por estações e diferentes metodologias apoiadas pelo uso das Tecnologias Digitais.

Os painelistas puderam trazer um pouco das atividades que estão sendo desenvolvidas em seus departamentos tanto em cursos de graduação, especialização e pós-graduação.

Foi possível observar durante as apresentações dos painelistas Luiz Carlos Pinto da Silva Filho (Depto. Engenharia Civil), Pantelis Varvaki Rados (Depto. Odontologia Conservadora) e Liane Margarida Rockenbach Tarouco (Depto. Informática Aplicada) a busca constante por aprimoramento e exploração das tecnologias digitais, visando oportunizar aos alunos que estas ferramentas pudessem ser empregadas como uma ferramenta cognitiva, levando-os a pensar a partir da utilização das tecnologias.

A manhã de workshop foi finalizada com a apresentação de ferramentas utilizando TIC's disponíveis e o repositório de conteúdo educacional digital na UFRGS - SEAD.

Deste modo, o presente artigo visa apresentar uma breve explanação dos assuntos levantados pelos painelistas, sobre as Tecnologias Digitais e a sua utilização como Ferramenta Cognitiva no contexto do ensino superior em diferentes cursos de graduação e pós-graduação.

Na segunda seção serão apresentadas as falas dos painelistas com considerações relevantes sobre o uso das Tecnologias Digitais no contexto das Engenharias, Odontologia e Informática. Posteriormente na seção seguinte, o uso das Tecnologias Digitais e sua utilização no contexto educacional. A seção três aborda o uso das Ferramentas Cognitivas e as suas contribuições para a aprendizagem. Para finalizar são apresentadas as considerações finais, perspectivas de trabalhos futuros e os aportes teóricos utilizados para subsidiar este breve relato.

\section{A abordagem dos painelistas: O uso das tecnologias na Engenharia, Odontologia e Informática}

Um dos principais objetivos ao proporcionar o Workshop de Inovação Pedagógica é poder oportunizar um momento de trocas de experiências e metodologias utilizadas entre professores e colaboradores de diferentes cursos, tendo em vista que nem sempre temos conhecimento do que acontece em cursos distintos ao nosso.

Deste modo, a partir da exposição realizada por cada um dos painelistas, foi possível verificar o uso de metodologias diferenciadas, além de atividades com o uso de tecnologias digitais, tal como descrito no decorrer do texto.

\subsection{Inovação Pedagógica com Tecnologias: Conhecendo um pouco do curso de Engenharia}

Diante das suas colocações sobre inovação pedagógica na área de Engenharia, o Professor Dr. Luiz Carlos Pinto da Silva Filho, diretor da Escola de Engenharia da UFRGS, fala sobre as mudanças tecnológicas que estão ocorrendo e da necessidade de acompanhá-las, pois elas acontecerão independente de estarmos preparados ou não e ter um planejamento para poder acompanhá-las é fundamental.

1 UFRGS - Universidade Federal do Rio Grande do Sul 
O curso de engenharia, está participando de um processo de modernização. Somente 8 universidades do Brasil foram contempladas. No Rio Grande do Sul somente a UFRGS e a Unisinos.

Diante do mercado de trabalho havia uma reclamação dos engenheiros de que saiam das instituições bons profissionais, no entanto sem terem uma maior noção de como integrar os conteúdos aprendidos, não percebiam relação e não tinham senso crítico em relação a determinadas coisas.

Os softwares matemáticos oportunizaram facilitar muitas coisas na Engenharia, porém dificultaram que os engenheiros pudessem sentir o senso físico do que estava sendo criado, incapacitando também de realizar a leitura de interfaces diante de todos os novos conhecimentos que são gerados diariamente.

Diante desta busca pela entrega de engenheiros capacitados, o currículo passou a ser organizado a partir da nova organização por competências e não mais por requisitos como anteriormente.

Ao trabalhar com os alunos, foi necessário trazer práticas e deixar que os mesmos pudessem explorar materiais e verificar a sua aplicação, como por exemplo o trabalho com resistência de materiais em que os alunos criavam suas próprias embalagens.

Os processos digitais têm transformado muito a relação entre as pessoas e a dinâmica de relacionamento entre o acesso à informação, isso, certamente irá trazer muitos impactos para a educação.

Para tanto, é necessário que professores de engenharia busquem por novas formas de ensinar seus alunos, diferente das que foram ensinados, de modo a poder modelar o programa do curso de engenharia atendendo, trazendo novas práticas para a centralidade do processo de ensino.

Visando chegar a estas formas foram realizadas visitas em diferentes instituições, até mesmo em outros países, para que se pudesse observar como que os cursos trabalhavam com os alunos e ainda quais as metodologias utilizadas para o ensino.

De acordo com o professor Dr. Luiz, a sala de aula deve ser um espaço crítico, com conteúdos sendo utilizados para a resolução de desafios e problemas. O professor já não é mais o detentor das melhores fontes de conhecimento, os alunos apenas com o uso de celular conseguem acessar inúmeros arquivos de renomadas universidades.

A questão principal se refere a como o aluno julga o que é bom e o que é ruim quando acessa conteúdos no espaço digital. O professor atualmente não consegue acompanhar o grande volume de informações gerados diariamente em papers e materiais da área, muito menos repassar todas estas informações aos seus alunos, diante disso, cabe a ele abandonar a ideia de que se ele não repassar as informações ao aluno, o aluno sairá da graduação deficiente.

É preciso pensar em formas de ensinar o aluno a "aprender a aprender", ou seja buscar por si próprio determinados conhecimentos que não são vistos em sala, mas que fazem parte de um processo contínuo de aprendizagem.

A vida útil dos conhecimentos aprendidos em engenharia é de no máximo 9 anos, sendo assim, ninguém sai da universidade pronto e formado, estes conhecimentos necessitam ser renovados de tempo em tempo. 
É importante diante destas modificações manter contato direto com os docentes, correr à frente de experiências e tentar familiarizar os docentes com as práticas para que ele consiga ser um mediador ao ministrar suas aulas, ter domínio e saber articular os conhecimentos.

\subsection{Inovação Pedagógica com Tecnologias: Metodologia Inovadora para Estudo e Treinamento na Odontologia}

A visão que grande parte das pessoas possuem sobre um cirurgião dentista é dele atuando com/sobre um paciente. No entanto, existem outras inúmeras atividades que são do dia-a-dia de um cirurgião-dentista que não fazem parte do nosso imaginário, porém ao final do curso, o objetivo é que o aluno esteja apto a atuar no mercado, a partir de um conjunto de habilidades e competências que são desenvolvidas.

O modelo curricular de formação na odontologia envolve uma área básica, pré-clínica e uma área clínica em uma zona de transcrição. Fundamentalmente na clínica se insere a patologia, onde o aluno precisa saber, entender e interpretar as alterações clínicas presentes, bem como alterações de imagem que são calcadas em modificações dos tecidos que são provocadas por mecanismos fisiopatológicos, que interferem nas alterações histopatológicas e que fazem parte do processo de formação do estudante.

A rotina de treinamento tradicional de estudos na patologia bucal, durante algum tempo foi baseada em entrar em um laboratório e fazer com que o estudante explorasse o microscópio, o que acabava gerando grande pavor, pois não agradava aos alunos ter que explorar algo que viram na escola, eventualmente, ou muitas vezes apenas por meio de fotografias e ao entrar para a faculdade necessitavam utilizar no processo de formação, estudar e começar a entender alterações projetadas eventualmente pelo professor.

$\mathrm{O}$ aluno ao enxergar procura absorver, treinar e fixar a partir da observação das imagens microscópicas.

A partir de uma necessidade, que foi ocasionada pelo uso do laboratório de aulas práticas, onde duas turmas necessitavam ter aula, um novo modelo de utilização de lâminas de microscopia pode ser colocado em prática.

Neste, um recurso de digitalização das lâminas das imagens de microscopia, possibilitou proporcionar aos alunos uma atividade diferenciada, mais inovadora, ou seja, através de uma atividade disruptiva, e de uma necessidade, diante do uso do laboratório de aulas práticas por duas turmas ao mesmo tempo, foi encontrado como alternativa aproveitar imagens que já estavam digitalizadas, e utilizá-las de modo novo e diverso do que era feito anteriormente.

O grupo da patologia e da biologia dos tecidos decidiu em conjunto oferecer as imagens que já estavam prontas e colocá-las em prática no curso noturno.

Hoje estas imagens digitalizadas são alvo de ciúmes entre os estudantes, pois como são filmagens o sistema permite que o aluno possa ver maior nitidez e detalhes que são alcançados com esta observação. Poder "caminhar" pela lâmina de microscopia permite treinar o aluno e fazer com que ele incorpore o conhecimento, obtendo maior segurança para saber interpretar as imagens radiográficas e clínicas.

Existem diferenças na parte do tecido conjuntivo de lesões, que o aluno precisa entender, precisa ter uma noção para conseguir diferenciar diferentes lesões. O uso de imagens e 
gravações irá permitir ao aluno visualizar não apenas no microscópio, mas também no seu computador ou celular, na hora, momento e quando ele achar mais adequado.

Este processo acabou trazendo algumas inquietações, principalmente porque as aulas de laboratório permitiam que o professor mantivesse uma proximidade com o estudante, que na área da saúde é um aspecto importante.

Além deste desafio, outros foram apontados pelo grupo, e necessitam ser observados diante desta prática inovadora com o uso de imagens: aquisição e retenção das informações; mudança na guarda do acervo, pois estes materiais são de pacientes e como serão guardados? Estes estarão disponíveis na internet, mas qual será o aspecto legal? Reflexo na atitude do aluno da clínica, como os alunos serão preparados para estar com antecedência no ambiente de laboratório, com uso de jaleco e com o seu material organizado para iniciar as atividades pontualmente no horário marcado?

Ao trabalhar com estas atividades novos desafios ainda virão, tendo em vista que os os alunos devem aprender ainda a fazer uma transição de como trabalhar com um paciente ao diagnosticar o que foi visto nas imagens.

\subsection{Inovação Pedagógica com Tecnologias: Mundo Imersivos, Agentes conversacionais e Internet das Coisas}

A iniciar sua fala a Professora Dra. Liane M. R. Tarouco expôs um histórico até a chegada da tecnologia propriamente dita. A professora ressalta que a primeira revolução foi com a chegada dos livros.

Ao ter acesso aos livros, os alunos não necessitavam mais seguir os sábios, embora o custo de livros fosse um pouco alto na época era possível que cada um buscasse pelo conhecimento, de acordo com a sua necessidade e interesse.

O conhecimento passou a estar disponível e cada um linha livre acesso, não era mais algo próprio somente de pensadores que transmitiam esses saberes.

A segunda revolução, foi marcada pela imprensa, a partir da impressão dos livros que antes eram escritos por monges. Com isso, os livros passaram a ficar mais acessíveis e o conhecimento passou estar disponível e cada vez mais ao alcance de todas as pessoas.

Poder estudar com o livro, independente do professor, já era uma metodologia utilizada, o que atualmente se assemelha a abordagem a qual denomina-se de sala de aula invertida (BERGMANN; SAMS, 2016);

Atualmente passamos por uma terceira revolução, onde o computador está disponível para a escrita e leitura de textos, podendo proporcionar a interação. A leitura pode ser transformada de um processo passivo para um processo ativo, desde marcações no texto até mesmo comentários e perguntas instigantes no decorrer dele.

As perguntas que são adicionadas, ficam para que os alunos possam ler e responder em cas,a e para que posteriormente uma discussão possa ser realizada durante a aula, conforme abordado por Mazur (1997) durante a exploração dos métodos Peer Instruction e Just-inTime Teaching.

Durante as atividades os alunos podem até mesmo produzir um outro texto, desde que trabalhem colaborativamente, com ferramentas como o Google Docs ou até mesmo o editor de texto colaborativo Metherpad, um plugin que foi desenvolvido pela Universidade Federal de São Carlos e pode ser integrado diretamente ao ambiente Moodle. 
Por meio da ferramenta, ao escreverem colaborativamente, os alunos cada um fica com uma cor, sendo que a cada parágrafo escrito o professor pode acompanhar pela cor e saber quem escreveu determinado trecho.

Pelo ponto de vista instrucional o uso do computador permitiu impactar a educação, pois além de proporcionar atividades que para os alunos pareciam mais instigantes, também possibilitava ajustar o tempo de acordo com o seu ritmo de aprendizagem.

Com a chegada de computadores e equipamentos mais robustos foi possível iniciar o trabalho com objetos de aprendizagem e animações, e atualmente animações para uso em ambientes mobile learning estão sendo desenvolvidas por meio de ferramentas de autoria MIT (Scratch e App Inventor).

Em 2018, o Hype Clicle das Tecnologias emergentes para a Educação, conforme o Gardner Group são: Realidade Aumentada, plataformas que utilizam a Inteligência Artificial de alguma forma, Assistentes virtuais que são utilizados para apoio, Realidade Mista combinando a Realidade Virtual e a IoT (Internet of Thing).

Diante disso, a inovação pedagógica se direcionou para a criação de mundos e de laboratórios virtuais, que possibilitam representar experiências onde o aluno possa testar e simular, tendo assim, a oportunidade de realizar um trabalho experimental mesmo diante da falta o material real ou mesmo de um laboratório real.

Esta ideia vem sido desenvolvida em diversos lugares, um exemplo é o EcoMUVE², utilizado pela Escola de Pós-Graduação de Harvard para ensinar alunos de ensino médio sobre ecossistemas. O ambiente virtual, possibilita ao aluno percorrer e explorar o ambiente, aprendendo Ciências, explorando e resolvendo problemas em ambientes realistas que recriam ambientes ecológicos, possibilitando aos alunos coletar informações e obter uma maior compreensão sobre problemas ambientais.

Os alunos individualmente ou aos pares podem explorar o ambiente, andar por ele, buscar indícios e tentar solucionar problemas a partir das evidências que ele mesmo encontra no ambiente virtual.

Em se tratando de exploração em ambientes virtuais e exploração de laboratórios virtuais, na Universidade Federal do Rio Grande do Sul tem sido desenvolvido o projeto AVATAR (Ambiente Virtual de Aprendizagem e Trabalho Acadêmico Remoto). O mesmo pretende investigar, testar e promover capacitação para que os laboratórios virtuais em ambientes imersivos possam ser utilizados, deixando professores e alunos mais próximos de laboratórios que muitas vezes não estão disponíveis em escolas de ensino médio, devido às dificuldades de custos, materiais e espaços.

O projeto utiliza o ambiente imersivo Open Simulator, um software livre que possibilita adicionar cenários com artefatos virtuais que podem ser manuseados e explorados pelos usuários. O principal objetivo é oportunizar a aprendizagem congregando laboratórios e mundos virtuais, com o uso de diversas tecnologias em que o usuário interage com conteúdos didáticos.

Ao utilizar o Ambiente Virtual, várias possibilidades de recursos multimídias também podem ser exploradas, tais como slides, vídeos, sites e páginas web. Adicionalmente, a Realidade

2 https://ecolearn.gse.harvard.edu/ecoMUVE Ambiente utilizado para trabalhar com alunos de Ensino Médio sobre ecossistemas e problemas ambientais. 
Aumentada também pode ser examinada por meio de dispositivos móveis, a partir da leitura de Qr Code, situações são apresentadas expandindo a realidade e trazendo mais informações aos alunos, independente de tempo e espaço.

O objetivo é que os objetos sejam modelados e fiquem o mais parecido possível para que possam ser importados para dentro do ambiente. Junto ao mesmo agentes ficam disponíveis para prestar auxílio, orientar e sanar dúvidas dos alunos em relação aos experimentos que serão desenvolvidos, recebendo feedbacks imediatos.

Os Chaterbots, agentes pedagógicos foram criados e organizados a partir de corpos linguísticos, palavras chaves e conceitos, de modo que tenham capacidade para responder perguntas e dúvidas básicas dos alunos diante de determinados conteúdos ao qual se refere o ambiente virtual em que está inserido.

Outra área de pesquisa também explorada junto ao Cinted é a IoT (Internet of Thing) por meio de sensores para a captura de passos observando o impacto causado em pessoas com necessidade de perder peso. Para tanto, um ambiente dentro do Open Simulator foi construído, os dados eram capturado, transmitidos ao celular e ao site do fabricante.

Através de um programa desenvolvido por uma aluna, os dados eram capturados e apresentados por meio de tabelas no mundo virtual. O usuário, ao comparecer na clínica uma vez por semana podia assistir, entrar no vídeo e acompanhar suas estatísticas, enquanto isso, o agente ficava sempre motivando o usuário através de mensagens de texto sms.

Ao entrar no ambiente o usuário também via outras pessoas fazendo exercícios, estas possuíam diferentes características físicas, para que ele percebesse outras pessoas que estavam lá pelo mesmo objetivo, perder peso. Ao entrar no ambiente eram sugeridos alguns exercícios que o usuário poderia realizar, e ao final o usuário poderia ver o seu avatar caminhando ou correndo na esteira, pois conforme estudos é importante ele se ver para sentirse motivado.

Outra área de pesquisa, tem sido a partir do uso de um sensor denominado NeuroSky Mindwave Mobile, em que a atenção e motivação estão sendo observadas. A partir do uso do equipamento é realizada uma leitura da emanação eletromagnética, um programa realiza a leitura e gera indícios para que se possa saber se o aluno está ou não prestando atenção. Já foram realizados testes com materiais disponibilizados no Moodle e posteriormente no mundo virtual, e pode-se observar que o aluno estava mais atento com o materiais disponibilizados por meio do mundo virtual.

Espera-se que por meio destes testes, com uma abordagem com um número significativo de alunos, se possa ter indícios do que dá e o que não dá certo diante do uso de recursos multimídias.

Um projeto que também está em desenvolvimento junto a UFRGS, é o projeto ALERTA, o mesmo permite que alunos possam fotografar e enviar problemas que encontram dentro do campus. O projeto tem embutido sensores participativos e uma rede de sensores, estes foram desenvolvidos por um aluno do curso de pós-graduação e medem a qualidade de $\mathrm{CO}_{2}$, temperatura, pressão, pois de acordo com a literatura, altos níveis de $\mathrm{CO}_{2}$ podem fazer com que o aluno fique mais dormente. Assim, uma sala de aula que possui ar condicionado, com um elevado número de alunos e sem renovação de ar, em duas horas pode atingir os níveis máximos de $\mathrm{CO}_{2}$. 
O projeto AVAECIM, de modo semelhante ao uso do Open Simulator, visa trabalhar com aplicações para uso no smartphone. Para tanto, recursos como Scratch e App Inventor estão sendo utilizados para desenvolver aplicações de laboratórios virtuais e ensejar que sejam realizadas atividades experimentais e que os próprios alunos e professores possam construir suas aplicações para laboratórios virtuais, tendo em vista as dificuldades de mantê-los devido aos custos.

É importante que estes recursos quando utilizados possam oferecer aos alunos boa interatividade, com comportamentos que se alteram em decorrências de cliques e dados que se modificam e são alimentados.

A experiência permite assim, uma nova estratégia de aprendizagem, o aluno tem a oportunidade de explorar estes materiais em casa e posteriormente vir para a sala de aula para discutir com os colegas e professores estes achados, compartilhando experiências e também fazendo uma análise crítica.

\section{O uso das Tecnologias Digitais para apoiar a aprendizagem}

Uma geração marcada pelo uso constante de tecnologias digitais e dispositivos móveis vem ingressando aos cursos de graduação. Esta geração certamente, teve a infância marcada por games e dispositivos que oportunizaram jogar vários jogos, sem a necessidade de sair de casa ou mesmo buscar por outras crianças para participar.

Situação esta que de acordo com Furió et al. (2015), fez com que estes jovens adquirissem competências e habilidades diferenciadas, criando um descompasso com as atividades que são desenvolvidas em sala de aula atualmente, isto porque ainda são educadas e ensinadas conforme uma metodologia de aprendizagem tradicional, onde as aulas expositivas prevalecem.

Segundo Ozdamle e Uzunboylu (2015), dispositivos móveis, telefones celulares, computadores pessoais e notebooks, estão sendo cada vez mais utilizados para fins educacionais. Laptops e demais dispositivos móveis têm se mostrado mais benéficos que computadores de mesa, pois permitem aos alunos aprender em qualquer momento e lugar. Adicionalmente, a acessibilidade a Internet oportuniza comunicação instantânea, já o sistema GPS acessa conteúdos relevantes de acordo com o local específico em que o aluno se encontra.

O uso das tecnologias móveis e sem fio, possibilitam que o ambiente de aprendizagem seja ampliado, oportunizando aos alunos realizar atividades em horários distintos e em qualquer ambiente.

Ainda conforme os autores citados, as tecnologias mobile learning, também possibilitam o desenvolvimento de trabalhos em ambientes cooperativos, oportunizando ao aluno aprender em qualquer lugar e momento.

Segundo Ozdamla e Uzunboylu (2015), a prática do autocontrole ao utilizar ferramentas interativas como smartphones, permitem aos alunos aprender por si próprios, e desempenham um importante papel na prática do comportamento metacognitivo.

Em um estudo comparativo entre a Sala de aula tradicional x A aprendizagem móvel, Furió et al. (2015), observou que os alunos ao utilizarem tablets e smartphone tiveram resultados significativos em relação aos conhecimentos que foram adquiridos. Os autores exploraram jogos e tecnologias móveis para ensinar e compararam com os conhecimentos adquiridos em uma sala de aula tradicional. No comparativo, ficou evidente que os alunos que participaram 
do jogo apresentaram motivações significativamente mais altas do que aqueles que desenvolveram atividades em um ambiente de sala de aula tradicional.

Outro aspecto importante a salientar, é que com mudanças e inovações tecnológicas que acontecem rapidamente, o mercado de trabalho global também está passando por transformações, exigindo funcionários preparados e com habilidades para explorar e aproveitar ao máximo tecnologias emergente, visando maior eficiência para a produção e consumo, bem como novas formas de expandir e ampliar mercados (WORLD ECONOMIC FORUM, 2018).

Diante destes aspectos, é importante oportunizar aos alunos diferentes formas de trabalho, tanto com o uso das tecnologias, como também de forma colaborativa e cooperativa, onde habilidades e competências tecnológicas sejam desenvolvidas, além de capacidades de trabalho coletivo que oportunizarão melhores chances de concorrer no mercado de trabalho.

\section{Ferramentas Cognitivas}

Atualmente as Tecnologias têm sido utilizada na educação de diferentes formas. No entanto observa-se que nem sempre todo o seu potencial é aproveitado ou mesmo elas são utilizadas como ferramentas para ampliar a estimulação cognitiva dos alunos, o que deveria de fato ser a sua função principal.

Drew (2019) ao conceituar Ferramentas Cognitivas ou Ferramentas Mentais (Cognitive Tools), salienta que estas ferramentas são projetadas pensando na aprendizagem orientada aos alunos, ou seja, que elas realmente possam ajudar e ampliar a estimulação da cognição de alto nível a partir do uso das tecnologias, ou mesmo após a sua utilização.

Já Korres (2019), em seus estudos, destaca que as Ferramentas Cognitivas são ferramentas computacionais que podem ser facilmente aprendidas, a partir da descoberta pelo aluno, com base na teoria de conhecimento construtivista.

O autor salienta ainda, que ao utilizar a aprendizagem apoiada em Ferramentas Cognitivas, as seguintes etapas devem ser incluídas: partir de um problema; coleta de dados, organização e análise dos mesmos, formação de conjecturas e conceitos e por fim formular conclusões acerca da pesquisa.

A partir de diferentes usos das tecnologias digitais, que se mostram cada vez mais versáteis, imersivas e personalizadas, observa-se que estas ferramentas podem se tornar parceiras no processo de construção de aprendizagem, apoiando o desenvolvimento do funcionamento mental.

Drew (2019), percebeu a partir de seus estudos que ao proporcionar o uso das tecnologias digitais aos alunos em alguma tarefa, seria possível que eles conseguissem reorganizar esquemas mentais. $\mathrm{O}$ autor deixa claro ainda em suas pesquisas, que as tecnologias digitais passa a ser ferramentas cognitivas quando auxiliam os alunos a organizar e reorganizar seus pensamentos, utilizando para tanto processos dos mais altos níveis cognitivos (BLOOM, 1984) servindo não apenas para facilitar tarefas.

Ao relacionar com os estudos de Korres (2019), percebe-se que quando solicita-se que um aluno faça uma pesquisa, investigue um problema ou solução, ele deverá criar algo novo a partir dos conhecimentos pré-existentes, necessitando assim de domínios cognitivos do mais alto nível, conforme definido anteriormente na Taxonomia de Bloom. 
Ao utilizar as tecnologias digitais como ferramentas cognitivas observa-se a possibilidade de experimentação por parte dos alunos, onde os mesmos possuem condições de levantar e verificar hipóteses, para a partir das suas experiências conseguirem construir seus próprios conhecimento.

\section{Considerações Finais}

O I Workshop de Inovação Pedagógica da Universidade Federal do Rio Grande do Sul, possibilitou à comunidade acadêmica, professores e funcionários conhecer um pouco mais do que vem sido trabalhado e de que forma as tecnologias digitais estão sendo utilizadas com os alunos nos mais variados cursos.

Diante do contexto atual o uso das tecnologias digitais proporciona que novas ferramentas, softwares e abordagens metodológicas possam ser utilizadas. No entanto, talvez pouco se saiba sobre o potencial e as diferentes formas de utilização destas ferramentas para que realmente venham desempenhar o seu papel e principal função no ensino, fazer com que os alunos possam utilizá-las como uma ferramenta em que o conhecimento pode ser apoiado e reorganizado utilizando as categorias de domínio cognitivo de níveis complexos, assim como definido por Bloom (1984).

A utilização das imagens para estudo e treinamento em microscopia, possibilita que as tecnologias sejam utilizadas como Ferramentas Cognitivas (DREW, 2019; KORRES, 2019), pois do modo em que são utilizadas, os alunos conseguem fazer constatações e construir seus conhecimentos sobre determinadas lesões que talvez não ficassem visíveis apenas com outro método ou mesmo com visualização em um microscópio.

Através de uma ferramenta dinâmica de visualização, o conhecimento é construído e os alunos necessitam buscar por evidências e aprender sobre determinadas características de lesões clínicas que se fazem presentes, e que futuramente precisarão interpretar ainda com maior precisão em seus pacientes.

Ao propor aos alunos que explorem Mundos Virtuais, por exemplo, de acordo também com as explanações de Nunes et al. (2016), diferentes situações podem ser proporcionadas, fazendo com que o aluno utilize recursos que não poderia utilizar diante da exploração e do uso de material concreto.

Situações fidedignas podem ser criadas e permitem que os alunos possam tomar decisões, se comunicar e interagir com demais colegas diante das situações que lhes são propostas, o que favorece também a aprendizagem colaborativa.

Adicionalmente, o trabalho com levantamento de problemas e investigações proporciona que o aluno se sinta instigado, e busque pela solução de um problema favorecendo a utilização de categorias de domínio cognitivo de maior complexidade, pois necessita utilizar estratégias das mais simples às mais complexas.

Deste modo, observa-se a partir dos exemplos de atividades desenvolvidas junto aos professores que apresentaram suas práticas com o uso das tecnologias digitais no painel "Inovação Pedagógica com Tecnologias", que este objetivo vem sendo desenvolvido com êxito, utilizando ferramentas apropriadas e em conformidade com estudos e tendências que vêm sendo apresentadas em pesquisas das referidas área. 


\section{References}

Avatar. (2019) "Página Oficial do Projeto AVATAR (Ambiente Virtual de Aprendizagem e Trabalho Acadêmico Remoto)”, Disponível em: <http://www.ufrgs.br/avatar>. (Acessado em 20/04/2019).

Avecim.(2019) "Página Oficial do Projeto AVAECIM (Ambiente Virtual de Aprendizagem Experimental em Ciências e Matemática)”, Disponível em: < http://www.ufrgs.br/avatar/agata-old >. (Acessado em 20/04/2019).

Bergmann, J. and Sams, A. (2016) "Sala de Aula Invertida. Uma Metodologia Ativa de Aprendizagem”, Edição: 1a ed. [s.l] LTC.

Bloom, B. S. (1984) "Sigma problem: The Research for Methods of Group Instruction as Effective as One-to-one Tutoring”, Educational Researcher., v. 13, n. 6, p. 4-16.

Furió, D. et al. (2015) "Mobile learnings vs. traditional classroom lessons: a comparative study.”. Journal of Computer Assisted Learning. doi: 10.1111/jcal.12071.

Drew, C. (2019) "Re-examining cognitive tools: New developments, new perspectives, and new opportunities for educational technology research.”. Australasian Journal of Educational Technology. 35 (2).

Korres, K. (2019) “Multivariable Analysis Methods on Identifying Factors and Groups of students in the environment of the Discovery Learning/Constructivistic Approach Using Cognitive Tools.”. EJERS, European Journal of Engineering Research and Science. Published on April, DOI: http://dx.doi.org/10.24018/ejers.2019.0.CIE.1289.

Mazur, E. (1997) “Perr Instruction: a user’s manual.”, Upper Saddle River: Prentice Hall.

Mit. (2017) “App Inventor”. http://appinventor.mit.edu/explore/front.html. (Acessado em 18/04/2019).

OpenSimulator, Non Player Characters. (2013). Disponível em http:// OpenSimulator.org/wiki. (Acessado em 18/04/2019).

Ozdamli, F. and Uzunboylu, H. (2015). M-learning adequacy and perceptions of students and teachers in secondary schools. In British Journal of Educational Technology. V. 46, N. 1, pages 159-172. doi: 10.1111/bjet.12136.

Nunes, E. P. D. D et al. (2016). Measuring Knowledge Acquisition in 3D Virtual Learning Environments. In IEEE Computer Graphics and Aplications, v. 36, ${ }^{\circ}$ 2, pages 58-67, MarApr. 